\title{
Transverse Cerebellar Diameter as an Independent Predictor of Gestational Age in Normal and IUGR Pregnancies
}

\author{
Manish Kumar ${ }^{1}$, Rohit Kaushik², Deepanshu Gupta ${ }^{3}$, Lalit Kumar ${ }^{4}$, Pramod Kumar ${ }^{5}$, Shobha Mukherjee ${ }^{6}$ \\ ${ }^{1}$ Assistant Professor, Department of Radiology, RMCH, Bareilly, ${ }^{2} J u n i o r$ Resident, Department of Radiology, RMCH, Bareilly, \\ ${ }^{3}$ Senior Resident, Department of Radiology, Hindu Rao hospital, New Delhi, ${ }^{4}$ Professor and HOD, Department of Radiology, \\ $\mathrm{RMCH}$, Bareilly, ${ }^{5}$ Professor, Department of Radiology, RMCH, Bareilly, ${ }^{6}$ Professor, Department of Obstetrics and Gynecology, \\ RMCH, Bareilly, Rohilkhand Medical College and Hospital, Bareilly, Uttar Pradesh- 243006, India
}

Corresponding author: Dr. Rohit Kaushik, Room no. 28, G-block, Rohilkhand Medical College and Hospital, Bareilly, Uttar Pradesh- 243006, India

DOI: http://dx.doi.org/10.21276/ijcmsr.2020.5.1.16

BY-NC-ND

How to cite this article: Manish Kumar, Rohit Kaushik, Deepanshu Gupta, Lalit Kumar, Pramod Kumar, Shobha Mukherjee. Transverse cerebellar diameter as an independent predictor of gestational age in normal and IUGR pregnancies. International Journal of Contemporary Medicine Surgery and Radiology. 2020;5(1):A68-A72.

\section{A B S T R A C T}

Introduction: Assessment of fetal maturity is quintessential in deciding whether to continue the pregnancy or terminate it, in case of complications such as fetal distress, pregnancy induced hypertension, diabetes, IUGR and Rh incompatibility. The sundry parameters which are currently being used to estimate GA include the Biparietal Diameter (BPD), Head Circumference (HC), Abdominal Circumference (AC) and Femur Length (FL). However, with advancing period of gestation, the variability in assessing the GA with these parameters keeps inflating. Transverse cerebellar diameter (TCD) is a new parameter for determining gestational age. TCD measurement is highly accurate in assessment of gestational age (GA), especially in cases where the last menstrual period (LMP) is not known. This study was done to evaluate the accuracy of transverse cerebellar diameter in assessment of fetal age in normal and IUGR pregnancies.

Material and Methods: This prospective cross-sectional study was conducted in the Department of Radiodiagnosis, Rohilkhand Medical College and Hospital Bareilly, U.P. from November 2017 to October 2018. The cases for the study included 100 pregnant women of gestational age 15 to 40 weeks who attended antenatal clinic at the Department of Obstetrics and Gynaecology, Rohilkhand Medical College \& Hospital, Bareilly, Uttar Pradesh.

Results and Conclusion: TCD showed a good correlation with other parameters like BPD, HC, AC and FL in normal pregnancies. TCD was seen to demonstrate the best correlation with GA as compared with other parameters in normal pregnancies $(r=$ 0.993, $\mathrm{p}<0.001)$ as well as IUGR pregnancies $(r=0.995, \mathrm{p}<0.001)$.

Keywords: Transverse Cerebellar Diameter, Gestational Age, IUGR Pregnancies

\section{INTRODUCTION}

Accurate dating of pregnancy is significantly essential in management of the obstetric patient, as many clinical decisions during pregnancy are dependent on gestational age. Assessment of fetal maturity is quintessential in deciding whether to continue the pregnancy or terminate it, in case of complications such as fetal distress, pregnancy induced hypertension, diabetes and $\mathrm{Rh}$ incompatibility. The sundry parameters which are currently being used to estimate gestational age (GA) include the Biparietal Diameter (BPD), Head Circumference (HC), Abdominal Circumference (AC) and Femur Length (FL) $\cdot{ }^{1-3}$ However, with advancing period of gestation, the variability in assessing the GA with these parameters keeps inflating. - $^{4-8}$

Transverse cerebellar diameter (TCD) is a new parameter for determining gestational age. Cerebellum is able to withstand the deformation caused by extrinsic pressure as it is surrounded by the dense petrous ridges and the occipital bone in the posterior cranial fossa. ${ }^{9}$ TCD measurement is highly accurate in assessment of GA, especially in cases where the last menstrual period (LMP) is not known. ${ }^{10}$ Intrauterine growth restriction (IUGR) or Fetal growth restriction (FGR) is a term used to describe a fetus that is abnormally small for gestational age, usually resulting from complications of placental insufficiency. The term small for gestational age (SGA) is used to describe a neonate whose weight is less than $10^{\text {th }}$ percentile for gestational age. The terms fetal growth restriction and small for gestational age are often used interchangeably. ${ }^{11}$

Antenatal diagnosis of IUGR is vital because of its association with increased perinatal morbidity and mortality including in-utero demise, brain injury, fetal distress, neonatal hypothermia, hyperbilirubinemia, hypoglycemia, and decreased immune function.

IUGR due to uteroplacental insufficiency or asphyxia results in centralization of blood flow in the fetus with sparing of brain at the expense of other body parts. ${ }^{12}$ Cerebellum is least affected even in acute asphyxia as the blood flow to the cerebellum is maintained. ${ }^{13}$ 
IUGR leads to early exhaustion of hepatic glycogen and subcutaneous fat resulting in decrease in AC. Hence, AC is contemplated as a sensitive parameter for early detection of IUGR. ${ }^{14-18}$

This study was done to evaluate the accuracy of transverse cerebellar diameter in assessment of fetal age in normal and IUGR pregnancies.

\section{MATERIALS AND METHODS}

This prospective cross-sectional study was conducted in the Department of Radiodiagnosis, Rohilkhand Medical College and Hospital Bareilly, U.P. from November 2017 to October 2018. The cases for the study included pregnant women of gestational age 15 to 40 weeks who attended antenatal clinic at the Department of Obstetrics and Gynaecology, Rohilkhand Medical College \& Hospital, Bareilly, Uttar Pradesh. 100 cases were included in the study out of which 78 were normal pregnancies and 22 were clinically suspected IUGR pregnancies.

\section{Inclusion criteria}

- Pregnancies of 15-40 weeks gestation with known last menstrual period.

- Clinically suspected intra uterine growth restriction.

\section{Exclusion criteria}

- Congenital malformations

- Multiple pregnancies

\section{Methods of collection of data}

The patient was examined in supine position, with a curvilinear array real time B-mode ultrasound machine "GE LOGIC V5" equipped with a 3.5 Mhz transducer. The conventional biometric measurements like BPD, HC, AC and FL were obtained along with TCD.

BPD was measured from outer to inner margin of the calvarium measured on an axial image of the fetal head is obtained at the level of the paired thalami, third ventricle, and cavum septum pellucidum.

$\mathrm{HC}$ was measured by using elliptical calipers to outline the outer edge of the skull on the same trans-axial view of the fetal head as the BPD.

$\mathrm{AC}$ was measured at the level of the stomach and intrahepatic portion of the umbilical vein on an axial image of the fetal abdomen. The elliptical calipers are placed outlining the outer surface of the skin around the abdomen.

FL was measured by placing the calipers at either end of the ossified diaphysis of the femur (fig-1).

Cerebellum is visualized as two lobules on either side of the midline in the posterior cranial fossa. Fetal TCD was measured after identifying the cerebellum in the posterior fossa by means of rotation of the transducer to approximately $30^{\circ}$ from the trans-axial plane that identifies the thalamus, the cavity of the septum pellucidum, third ventricle and cistern magna. The electronic calipers were placed on the outer margins of the cerebellar hemispheres and the widest measurement was taken (fig-2).

GA and estimated fetal weight (EFW) were derived from the measured biometric parameters by the ultrasound machine. Clinically suspected IUGR cases were confirmed for fetal growth restriction in cases where the estimated fetal weight was below the $10^{\text {th }}$ percentile for that gestational age

\section{STATISTICAL ANALYSIS}

Appropriate statistical methods were used for analysis using SPSS version 25 statistical package for windows. Graphs and tables were generated using Microsoft Word and Excel.

TCD was compared with BPD, HC, AC, FL values in normal pregnancies using Karl Pearson's correlation. The measured TCD, BPD, HC, AC and FL values were also compared with GA using Karl Pearson's correlation in both normal and IUGR pregnancies. Results having $\mathrm{P}<0.05$ are considered significant.

\section{RESULTS}

In 78 normal pregnancies, good correlation was observed between TCD and other biometric parameters (Table 1).

Each parameter (BPD, HC, AC, FL and TCD) revealed a strong relationship with GA and TCD was seen to demonstrate the best correlation with GA (Table 2). Scatter diagrams were obtained and polynomial equations were derived to show relationship between GA and other

\begin{tabular}{|l|c|c|}
\hline Parameters compared & ' $\mathbf{}$ ' & p value \\
\hline TCD vs BPD & 0.971 & $<0.001$ \\
\hline TCD vs HC & 0.966 & $<0.001$ \\
\hline TCD vs AC & 0.986 & $<0.001$ \\
\hline TCD vs FL & 0.978 & $<0.001$ \\
\hline \multicolumn{2}{|c|}{ Table-1: Correlation of TCD with BPD, HC, AC and FL in normal } \\
pregnancies. \\
\hline
\end{tabular}

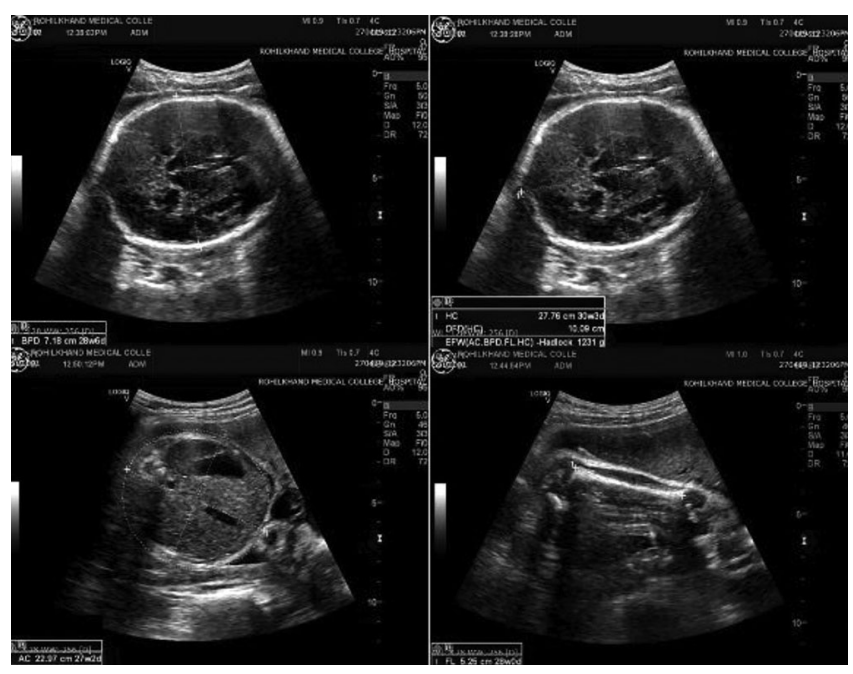

Figure-1: Ultrasonographic measurement of BPD, HC, AC and FL.

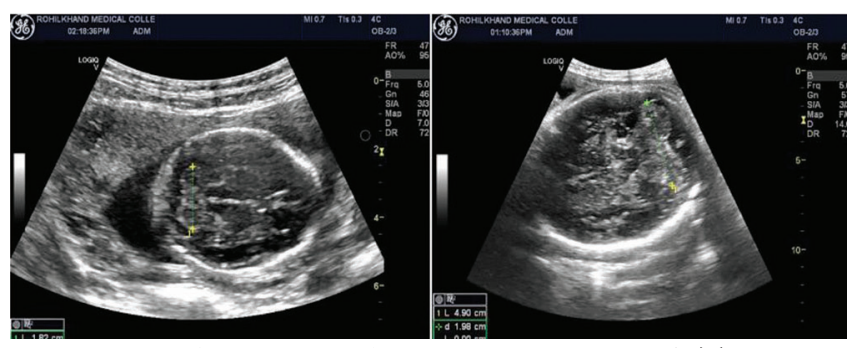

Figure-2: Ultrasonographic measurement of Transverse Cerebellar Diameter in second and third trimester. 


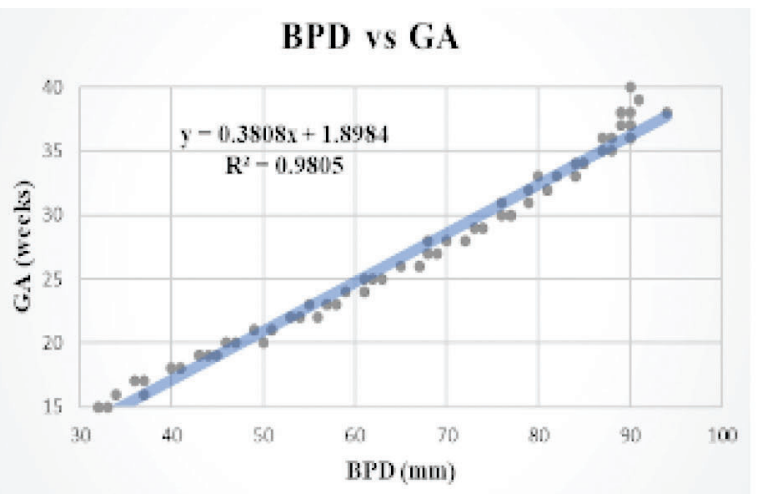

AC vs GA

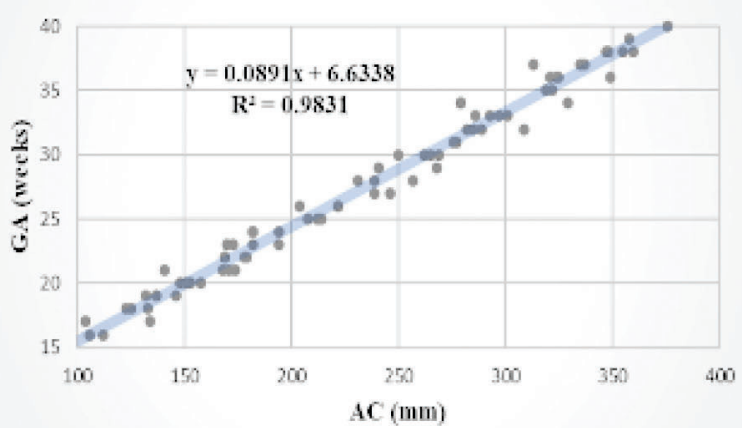

HC vs GA

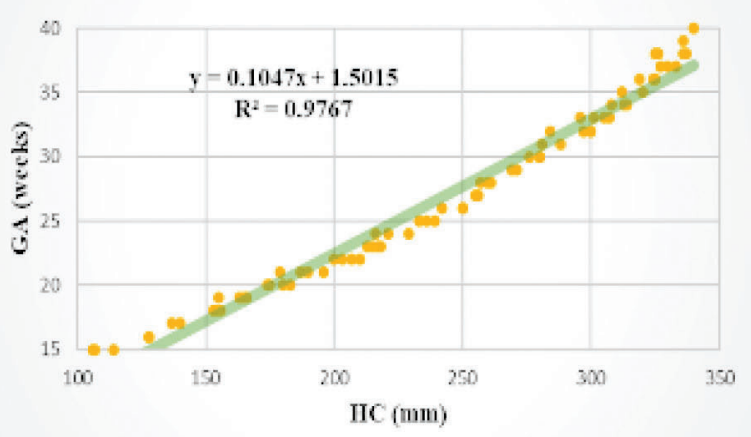

FL vs GA

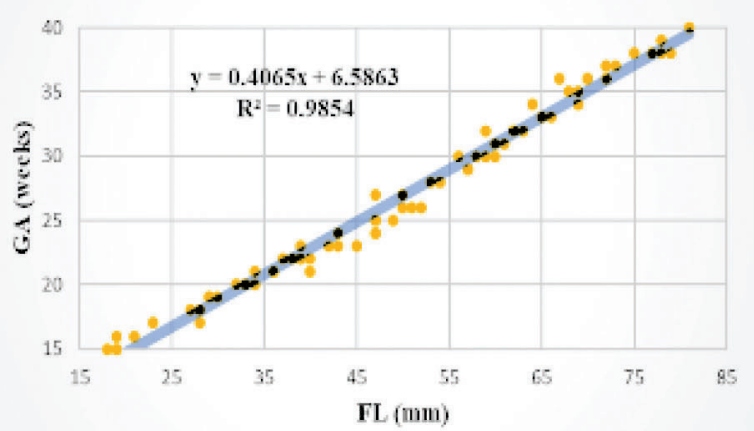

Figure-3: Scatter diagram showing correlation of GA with BPD, HC, AC and FL.

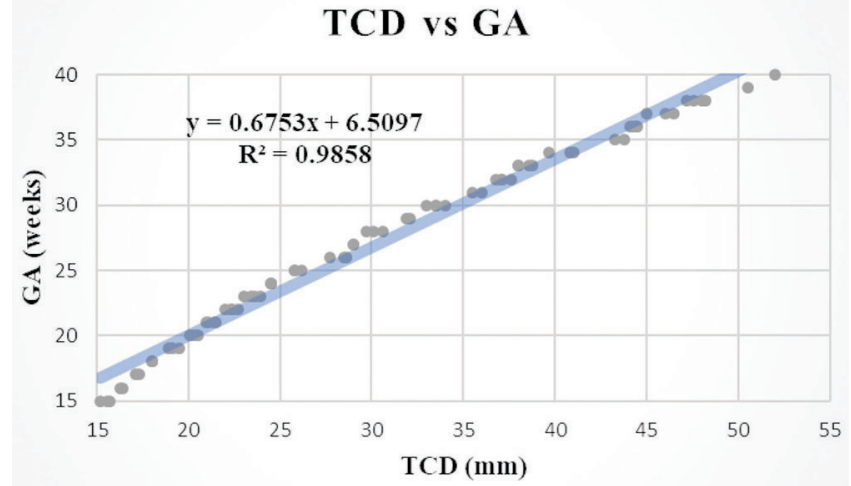

Figure-4: Scatter diagram showing correlation between GA and TCD.

\begin{tabular}{|l|c|c|}
\hline Parameters compared & 'r' & p value \\
\hline GA vs BPD & 0.990 & $<0.001$ \\
\hline GA vs HC & 0.988 & $<0.001$ \\
\hline GA vs AC & 0.991 & $<0.001$ \\
\hline GA vs FL & 0.992 & $<0.001$ \\
\hline GA vs TCD & 0.993 & $<0.001$ \\
\hline \multicolumn{2}{|c|}{ Table-2: Correlation of GA with BPD, HC, AC, FL and TCD in } \\
normal pregnancies. \\
\hline
\end{tabular}

\begin{tabular}{|l|c|c|}
\hline Parameters compared & ' $\mathbf{c}$ ' & p value \\
\hline GA vs BPD & 0.825 & $<0.001$ \\
\hline GA vs HC & 0.856 & $<0.001$ \\
\hline GA vs AC & 0.993 & $<0.001$ \\
\hline GA vs FL & 0.878 & $<0.001$ \\
\hline GA vs TCD & 0.995 & $<0.001$ \\
\hline Table-3: Correlation of GA with BPD, HC, AC, FL and TCD in \\
IUGR pregnancies. \\
\hline
\end{tabular}

\begin{tabular}{|l|c|c|}
\hline Parameter & $\begin{array}{c}\text { IUGR Cases with } \\
\text { values below } \mathbf{1 0}^{\text {th }} \\
\text { percentile }\end{array}$ & $\begin{array}{c}\text { IUGR Cases with } \\
\text { values within normal } \\
\text { range }\end{array}$ \\
\hline BPD & 10 & 12 \\
\hline HC & 9 & 13 \\
\hline AC & 22 & 0 \\
\hline FL & 9 & 13 \\
\hline TCD & 2 & 20 \\
\hline $\begin{array}{c}\text { Table-4: IUGR cases with BPD, HC, AC, FL and TCD values less } \\
\text { than 10th percentile on comparison with normograms derived } \\
\text { from normal pregnancies. }\end{array}$ \\
\hline \multicolumn{2}{|c}{} \\
\hline
\end{tabular}

parameters (fig-3,4).

Normograms were derived for $\mathrm{BPD}, \mathrm{HC}, \mathrm{AC}, \mathrm{FL}$ and TCD from the sonographically measured data in normal pregnancies.

In 22 IUGR pregnancies, TCD was seen to demonstrate the best correlation with GA ( $r=0.995)$ in IUGR pregnancies. The correlation was observed to be less strong between GA and other parameters as compared to TCD (Table 3).

On comparison with the normograms derived from normal pregnancies, it was observed that 10 out of 22 IUGR cases were below the tenth percentile for BPD, 9 cases were below the tenth percentile for $\mathrm{HC}$ and 9 cases were below the tenth percentile for FL. AC was found to be below the tenth percentile in all the IUGR cases. Only in 2 out of 22 IUGR cases, the value of TCD was noted to be below the tenth percentile (Table 4).

\section{DISCUSSION}

Accurate gestational dating is of prime significance and forms the mainstay for management of pregnancies especially in 
fetuses with intrauterine growth restriction.

The considerable variability in the length of the follicular phase of the menstrual cycle and the inconstant timing of ovulation and fertilization in relation to the LMP, as well as the often inaccurate method of determining LMP by women, make the LMP a very insecure basis for estimating gestational age. ${ }^{19}$

The biometric parameters that are routinely used for estimation of gestational age are $\mathrm{BPD}, \mathrm{HC}, \mathrm{AC}$ and FL. However, each of these parameters are non-specific with limitations in setting of inconsistency between clinical and ultrasonographic age. These parameters are also influenced by fetal growth, configuration of skull and external compressive forces as in certain abnormal presentations. ${ }^{20}$

Cerebellum lies in the posterior cranial fossa, surrounded by the dense petrous ridges and occipital bone so it can withstand deformation by extrinsic pressure better than the parietal bones. ${ }^{21} \mathrm{TCD}$ is a unique parameter for estimating the gestational age of fetus.

In this study, a perfect linear relationship was found between the cerebellar growth and gestational age (in weeks) from 15 weeks of gestation onwards. TCD and gestational age showed a good correlation between them $(r=0.993$, $p$ value $<0.001)$.

Reece et al found curvilinear relationships between the transverse cerebellar diameter, and the gestational age, the biparietal diameter, and the head circumference and inferred that cerebellar measurement is independent of the shape of fetal head and may be used in the estimation of gestational age. ${ }^{22}$ In our study, TCD and gestational age showed a good correlation $(r=0.993, p$ value $<0.001)$. A good correlation was also observed between TCD and BPD $(r=0.971$, $p$ value $<0.001)$ and between TCD and HC ( $r=0.966$, $\mathrm{p}$ value < 0.001). TCD can be used where it is difficult to measure $\mathrm{BPD}$ or in cases where there are variations in size and shape of head.

Malik et al compared the results of predicted gestational age by BPD, FL and AC with actual gestation and observed that gestational age measured by TCD consistently correlated with that measured by BPD, FL and AC. ${ }^{23}$ This correlation has also been observed in this study between TCD and FL $(\mathrm{r}=0.978, \mathrm{p}$ value $<0.001)$ and between TCD and AC ( $\mathrm{r}=$ $0.986, \mathrm{p}$ value $<0.001)$.

The major factor for increase in the fetal weight after 28 weeks of gestation is fetal fat gain. There is deposition of fat in the subcutaneous tissue of the abdomen along with glycogen deposition in the liver. In cases of IUGR, the depletion of hepatic glycogen and subcutaneous fat stores leads to an early decrease in the $\mathrm{AC}$ and a consequent decrease in the fetal weight. ${ }^{24,25}$

Hadlock et al observed 30 growth-restricted fetuses and found $\mathrm{AC}$ to be the most sensitive indicator of fetal growth restriction. Estimated fetal weight was also found to be a relatively sensitive indicator of fetal growth restriction in this study. ${ }^{14}$

Similar observations were made in our study where both AC and $\mathrm{EFW}$ were below the $10^{\text {th }}$ percentile value for gestational age in all the 22 IUGR cases.

In normal pregnancies, there is high resistance circulation with continuous forward flow in the fetal brain which is also seen throughout the cardiac cycle. When fetal hypoxemia is present in growth restriction, blood flow redistribution occurs, a phenomenon known as the "brain-sparing reflex", to compensate for the decrease in available oxygen. There is preferential redistribution of blood flow to the brain, heart, and adrenal glands at the expense of the peripheral circulation. This phenomenon is seen in asymmetrical IUGR thereby leading to a normal or a near normal BPD and HC. ${ }^{26}$ Similar observations were made in our study in cases of asymmetrical IUGR, where BPD and HC were found close to those of normal pregnancies of similar gestational age.

Mona Al Sayed Elkafrawy et al showed a highly significant correlation between transverse cerebellar diameter and gestational age in normal and IUGR fetuses. ${ }^{23}$

Our study shows that TCD is a good marker for estimation of gestational age as it correlates well with significant value $(r=$ 0.995 , p value $<0.001)$. On comparison with the normograms derived from normal pregnancies, it was observed that 10 out of 22 IUGR cases were below the tenth percentile for BPD, 9 cases were below the tenth percentile for $\mathrm{HC}$ and 9 cases were below the tenth percentile for FL. The value of TCD was noted to be below the tenth percentile in only 2 cases. Thus, TCD remains relatively unaffected and is superior to other growth parameters in cases of IUGR pregnancies.

Hill et al studied 44 SGA fetuses, found reduced TCD in $59 \%$ cases, and inferred that TCD cannot be used as a parameter to estimate gestational age in SGA fetuses. ${ }^{27}$

Lee et al investigated 19 SGA fetuses and concluded that TCD is a reliable predictor of gestational age in fetuses with asymmetric IUGR, but not in fetuses with symmetric IUGR. ${ }^{28}$

The results in our study are however discordant with those of the above two studies. We observed that TCD reliably predicted the true gestational age in $66.67 \%$ of symmetric IUGR cases and in all the cases (100\%) of asymmetric IUGR fetuses.

\section{CONCLUSION}

TCD is a reliable method of determining gestational age in normal pregnancies at 15 to 40 weeks of gestation. It can be used in cases where it is difficult to measure BPD (like in breech presentation) or in cases where there are variations in size and shape of head (like excessive moulding and dolicocephaly). Also, TCD is unconstrained with problems encountered with the measurement of FL (like inclusion of unossified epiphysis). TCD is a valuable parameter to estimate the gestational age in IUGR fetuses and is superior to other parameters.

\section{REFERENCES}

1. Degani S. Fetal biometry: clinical, pathological, and technical considerations. Obstetrical \& gynecological survey. 2001;56(3):159-67.

2. Hohler CW. Ultrasound estimation of gestational age. Clin Obstet Gynaecol. 1984; 27(2):314-26.

3. Lerner JP. Fetal growth and well-being. Obstetrics and Gynecology Clinics. 2004 Mar 1;31(1):159-76.

4. Hadlock FP, Deter RL, Harrist RB, Park SK. Fetal 
abdominal circumference as a predictor of menstrual age. AJR Am J Roentgenol. 1982; 139(2):367-70.

5. Hadlock FP, Deter RL, Harrist RB, Park SK. Fetal biparietal diameter: a critical re-evaluation of the relation to menstrual age by means of real-time ultrasound. Ultrasound Med. 1982;1(3):97-104.

6. Hadlock FP, Deter RL, Harrist RB, Park SK. Fetal head circumference: relation to menstrual age. AJR Am J Roentgenol R. 1982; 138(4):649-53.

7. Deter RL, Harrist RB, Hadlock FP, Carpenter RJ. Fetal head and abdominal circumferences: II. A critical reevaluation of the relationship to menstrual age. J Clin Ultrasound. 1982; 10(8):365-72.

8. Hadlock FP, Deter RL, Harrist RB, Park SK. Fetal femur length as a predictor of menstrual age: sonographically measured. AJR Am J Roentgenol. 1982; 138(5):875-8.

9. Reddy RH, Prashanth K, Ajit M. Significance of foetal transcerebellar diameter in foetal biometry: A pilot study. Journal of Clinical and Diagnostic Research: JCDR. 2017;11(6):TC01-4.

10. Chavez MR, Ananth Cv. Fetal transcerebellar diameter measurement with particular emphasis in the third trimester: A reliable predictor of gestational age. American journal of obstetrics and gynecology 2004; 191: 979-84.

11. Norton ME. Callen's Ultrasonography in Obstetrics and Gynecology. $6^{\text {th }}$ ed. Elsevier Health Sciences; 2016. Chapter 6, Fetal biometry and growth; p.126.

12. Campbell AGM, Dawes GS, Fishman AP, Hyman AI. Regional distribution of blood flow in mature fetal lamb. Circulation Res 1984;21(3):229.

13. Behrman RE, Lees MH, de Peterson EN, Lannoy CW, Seeds AE. Distribution of the circulation in the normal and asphyxiated primate. Am J Obstet Gynecol 1970;108(1):956-96.

14. Hadlock FP, Deter RL, Harrist RB, Roecker E, Park SK. A date-independent predictor of intrauterine growth retardation: Femur length/abdominal circumference ratio. Am J Roentgenol 1983;141(5):979-84.

15. Tongsong $\mathrm{T}$, Wanapirak C, Thongpadungroj T. Sonographic diagnosis of intrauterine growth restriction (IUGR) by fetal transverse cerebellar diameter (TCD)/ abdominal circumference (AC) ratio. Int J Gynaecol Obstet 1999;66(1):1-5.

16. Campbell S, Wilkin D. Ultrasonic measurement of fetal abdominal circumference in the estimation of fetal weight. Br J Obstet Gynaecol 1975;82(1):689-97.

17. Woo JS, Wan CW, Cho KM. Computer-assisted evaluation of ultrasonic fetal weight prediction using multiple regression equations with and without the fetal femur length. J Ultrasound Med 1985;4(6):65-7.

18. Hussain KA, Kadiyala S, Lakshmi AY, Hindumathi M. Fetal transcerebellar diameter to abdominal circumference ratio (TCD/AC) and to femur length ratio $(\mathrm{TCD} / \mathrm{FL})$ in the assessment of normal fetal growth. J NTR Univ Health Sci 2019;8(5):5-10.

19. Geirsson RT. Ultrasound instead of last menstrual period as the basis of gestational age assignment. Ultrasound in Obstetrics and Gynecology: The Official Journal of the International Society of Ultrasound in Obstetrics and Gynecology. 1991;1(3):212-9.
20. Sharma G, Ghode R. Foetal transcerebellar diameter and transcerebellar diameter - abdominal circumference ratio as a menstrual age independent parameter for gestational age estimation with grading of cerebellar maturity. Int J Reprod Contracept Obstet Gynecol. 2015;4(6):2036-40.

21. Agrawal C, Agrawal KK, Gandhi S, Chaudhary S. Correlation between ultrasonography measured transcerebellar diameter of foetus with early and late gestational age. Int J Reprod Contracept Obstet Gynecol 2015;4(5):2010-3

22. Reece EA, Goldstein I, Pilu G, Hobbins JC. Cerebellar measurements with ultrasonography in the evaluation of fetal growth and development. AM.J. Obstet. Gynecol 1987;156(1): 1065-9.

23. Elkafrawy MAS, Ahmed AAM, Soliman AH. Correlation study of Transverse Cerebellar Diameter with Gestational Age in Normal and Growth Restricted Fetuses (IUGR). J Am Sci 2015;11(12):163-8.

24. Meyer WJ, Gauthier DW, Goldenberg B, Santolaya J, Sipos J, Cattledge F. (1993). The fetal transverse cerebellar diameter/abdominal circumference ratio: a gestational age-independent method of assessing fetal size. J. Ultrasound Med. 1993;12(7):379-82.

25. Campbell S, Thomas A. Ultrasound measurement of the fetal head to abdomen circumference ratio in the assessment of growth retardation. BJOG: An International Journal of Obstetrics \& Gynaecology. 1977;84(3):165-74.

26. Uquillas KR, Grubbs BH, Prosper AE, Chmait RH, Grant EG, Walker DK. Doppler US in the Evaluation of Fetal Growth and Perinatal Health. RadioGraphics 2017;37(6):1831-8.

27. Hill LM, Guzick DA, Rivello DA, Hixson JO, Peterson CA. The transverse cerebellar diameter cannot be used to assess gestational age in the small for gestational age fetus. Obstetrics and gynecology. 1990;75(3 Pt 1):32933.

28. Lee W, Barton S, Comstock CH, Bajorek S, Batton D, Kirk JS. Transverse cerebellar diameter: a useful predictor of gestational age for fetuses with asymmetric growth retardation. Am J Obstet Gynecol, 1991; 165(4):1044-50.

\section{Source of Support: Nil; Conflict of Interest: None}

Submitted: 29-11-2019; Accepted: 02-01-2020; Published online: 04-02-2020 